\title{
Principles of Sustainable Learning Object Libraries
}

\section{Deana Namuth, Susan Fritz, James King, and Amy Boren University of Nebraska-Lincoln, NB, USA}

\author{
dnamuth@unl.edu smfritz@unlnotes.unl.edu \\ jking1@unl.edu aboren@unlnotes.unl.edu
}

\begin{abstract}
As the effectiveness of learning objects in enhancing education becomes better understood, it will be critical to more fully develop the predictive characteristics of learning object usage by diverse instructors and their long-term sustainability in learning object repositories. Additionally, the advancement of scholarship in these endeavors - a critical factor for faculty to consider - has frequently been overlooked. In this paper we explore these issues by examining the technical and human aspects of The Library of Crop Technology (http://croptechnology.unl.edu) and other repository models. While studies have been conducted to research the impacts of animations on student learning, teacher perceptions of such learning objects have not been examined. An online survey instrument was created and sent to those who had downloaded animations from the Library of Crop Technology. Data collected indicated that educational, animated, learning objects are an effective and sustainable means of meeting a wide array of educator needs. This study identified a template of science content, organization, creation of interest in the topic, visual appeal, effectiveness for teaching a topic, and ease of use as being important to the overall teacher perception of the learning object's quality. The very positive evaluation received from the users, coupled with their indication of returning to the site multiple times and recommending it to their colleagues, further suggests that the public repository is a model to continue pursuing. An important, but often overlooked, concept in the development of repositories is the dynamics of long term sustainability and scholarly contributions. A second study researched team development and institutional commitments which play a role in the long term stability of this learning object repository. A model integrating team development, institutional commitments, learning object development and scholarship recognition is proposed.
\end{abstract}

\section{Introduction}

Advancements in information technology and greater understanding of the pedagogical principles which underpin successful distance education have led to the creation of innovative instructional

Material published as part of this journal, either on-line or in print, is copyrighted by the publisher of the Interdisciplinary Journal of Knowledge and Learning Objects. Permission to make digital or paper copy of part or all of these works for personal or classroom use is granted without fee provided that the copies are not made or distributed for profit or commercial advantage AND that copies 1) bear this notice in full and 2) give the full citation on the first page. It is permissible to abstract these works so long as credit is given. To copy in all other cases or to republish or to post on a server or to redistribute to lists requires specific permission and payment of a fee. Contact Publisher@ijklo.org to request redistribution permission. approaches in distance delivery. One such innovative approach is the use of animated learning objects. The idea of producing small, bite-sized pieces of portable, electronic, educational materials which address a single learning objective has been quickly embraced. Even before the term "learning object" was coined, educators had begun to think of utilizing learning objectives rather than entire curriculums, 
courses, or even lectures to enhance the learning experiences of their students. The realization that learning objects can be shared among colleagues for use in a variety of educational contexts, for both distance and face to face settings, has helped faculty utilize limited resources and time more effectively to meet the growing educational needs of diverse clientele. A great advantage of learning objects is that they can be used over and over by many different instructors and learners from around the globe. When learning objects are grouped into a library, or some type of repository, users can explore the particular learning activities and specific content packages which best meet their individual learning goals (Schaffer \& Douglas, 2004; Spector, 2002).

The sciences, though, pose unique educational challenges in distance education because their concepts are often more easily grasped when accompanied by demonstrations or hands-on activities. These can be difficult to replicate in a distance delivery setting, where learners are unable to directly interact with the activity. In addition, some topics such as in genetic engineering or soil microbiology describe processes at the molecular level which are not directly visible. In a traditional setting, an instructor may try to use drawings or the chalkboard to clarify such concepts; but this has been problematic in distance-delivered contexts. However, a portable learning object can assist learning in both a traditional as well as a distance delivered venue. Unfortunately, the creation of effective individual objects which address the unique needs of science students often require sizeable investments of both time and money. Due to the resources necessary to create learning objects addressing science topics, the long-term sustainability of these objects and their collections into repositories is of the utmost importance. "Sustainability" is a term used in the agricultural sciences to describe a philosophy which rests on the principle of meeting the needs of the present without compromising the ability of future generations to meet their own needs (Feenstra et al., 1997). It is a holistic systems approach implying interdisciplinary efforts in research and education. (http://www.sarep.ucdavis.edu/concept.htm ). Applying this perspective to learning objects and learning object repositories, interdisciplinary efforts in areas of information technology, science technology, and educational research are required to create materials which not only meet immediate educational needs, but also assist in meeting other needs without reinventing processes or objects themselves.

This paper will address sustainability themes of scientific learning object repositories by exploring some vital, but often overlooked, components of the repository construction process. These components include: 1) characteristics of the learning objects themselves, both technical and content based, 2) recognition for university faculty scholarship contributions, and 3) team dynamics and institutional commitment. First, we will direct our attention to the collections of objects into repositories. Next, we will continue our discussion by specifying the characteristics of individual objects with the greatest potential of long term use and adoption by diverse audiences. Finally, issues pertaining to institutional commitment and team building, which are the intangible factors in the sustainability of learning object repositories, will be addressed.

\section{Defining Learning Object Repositories}

For their potential utility to be fully realized, learning objects need to be housed in collections that are easily accessible and searchable by the intended users. Individual learning objects not housed or linked within a repository will be more difficult to locate and utilize for those users beyond the immediate setting for which the objects have been originally designed. Furthermore, repositories provide a means for individual creators of learning objects to collaborate and extend their limited resources. Currently there exist several repositories on the Web which are open to public access. There are also private repositories which require fees for use.

It is important to distinguish between types of repositories (see Table 1). To date, there are two broad categories into which a repository can be placed. First, there exist true repositories which are usually characterized by their focus on particular subjects or themes and physically house the 
individual learning objects. For example, the Library of Crop Technology (http://croptechnology.unl.edu) houses learning objects dealing with topics in areas related to crop science such as genetics, integrated weed management, and food science. In another example, The Mayo Clinic has a repository for learning objects that educate on health related areas (http://www.mayoclinic.com/programsandtools/slideshows.cfm). In both of these examples, an organization has created the objects and oversees their maintenance.

\begin{tabular}{|l|l|l|}
\hline & Repository & Clearinghouse \\
\hline \multirow{3}{*}{ Characteristics } & Self contained & Reference/pointer/clearinghouse \\
\cline { 2 - 3 } & Local needs & Storage \\
\cline { 2 - 3 } & Developed by individuals & Like a dictionary \\
\hline \multirow{2}{*}{ Examples } & Library of Crop Technology & Merlot \\
\cline { 2 - 3 } & Mayo Clinic & NSF \\
\hline
\end{tabular}

Table 1: Two types of learning object organizational levels.

The term 'repository' is almost a misnomer for the second category; perhaps 'clearinghouse' would be a more suitable term. A 'clearinghouse' repository serves as a type of gateway to other repositories or individual learning objects. In and of themselves, they contain no learning objects, but they do serve as an excellent gateway for locating effective learning objects and repositories addressing a myriad of topics. Examples of these types of clearinghouse repositories include National Science Digital Library (http://nsdl.org/) and Merlot (http://www.merlot.org/Home.po). The National Science Digital Library (NSDL) mission statement affirms that it "was created by the National Science Foundation to provide organized access to high quality resources and tools that support innovations in teaching and learning at all levels of science, technology, engineering, and mathematics education." (http://nsdl.org/about/) Merlot is also a clearinghouse for digital objects in sciences and other subject areas, with the added component of providing a peer-review of the materials. "MERLOT is also a community of people who are involved in education. Community members help MERLOT grow by contributing materials and adding assignments and comments."(http://www.merlot.org/Home.po)

\section{Repository Content Focus}

If a goal of a learning object repository is to provide supporting educational materials addressing foundational knowledge, it will have a greater chance of longer sustainability than a repository addressing a 'hot button' topic. Markwell and Brooks (2003) described two types of ".edu" sites: those addressing broader issues for a more global audience and those more narrowly focused to address a local issue. The more globally targeted sites had longer sustainability. Therefore, when setting out to establish a learning object repository it is critical to know who is being served and the nature of their particular needs. Is the mission of the repository focused more on building knowledge or building awareness? Two learning object repositories worked in collaboration to address a hot topic in early 2000. The Library of Crop Technology addressed more in depth, academic educational needs of the science behind genetically modified organisms (http://croptechnology.unl.edu); Transgenic Crops (http://www.colostate.edu/programs/lifesciences/TransgenicCrops) also developed educational materials on genetically modified organisms but for the more general public type of audience to address their specific questions and concerns. 
Together the two projects effectively met a very pressing educational need. However, after the urgency to understand genetically modified organisms has passed, it is likely that the Transgenic Crops site will no longer be maintained nor enhanced since it has fulfilled its shorter mission. In contrast, the Library of Crop Technology, whose underlying mission was plant science education, will continue to grow as new materials are developed addressing other plant science related topics, including genetics. Since the Transgenic Crops site was more issue oriented, it was put online much more quickly in order to address educational needs concerning the issue. This is a very important characteristic of an issue type of repository. It needs to be very mobile and quick to come online, otherwise the small window of opportunity will be missed. In contrast, the Library of Crop Technology was much slower to come online and be widely adopted. Unlike the issueoriented repository, the Library of Crop Technology is focused on building in-depth knowledge. It walks the learner through a process of discovery and understanding of science principles. Learners are drawn in because of a controversial contemporary issue, but along the way they learn specific science principles which they can then apply to other, similar circumstances. Therefore, when developing a learning object repository, it is important to have a clear goal in mind for the repository's function.

\section{Learning Object Utility}

In order for repositories to be sustainable, the individual learning objects of which they are comprised should carry certain characteristics which facilitate longevity. Some of these are technical in nature, such as software and hardware considerations, as well as accessibility in searches with adequate metadata records. The other characteristics are more related to instructional design and content, referred as "reusability" (Sicilia \& Garcia, 2003). We introduce the term "utility" to describe a learning object's expanded use beyond that of the initial intended audience or educational setting, which embraces both of these characteristics. Therefore, "utility" encompasses both the learner and educator aspects of the educational process, as well as technical features inherent of electronic media. These next sections will look into greater depth at three aspects contributing to the final utility of an object: 1) the roles of information technology, 2) impact on actual learning and 3) educator perceptions of learning object use.

\section{Information Technology Factors}

The first factor in a learning object's sustainability is the information technology utilized in the development. Although objects should be designed with the educational content goals, in mind first and information technology capability considerations second, having support staff with expertise in programming and software packages is needed to ensure greater long term sustainability. For example, it is critical for support staff to maintain a keen awareness of international standards being developed and adopted in the field to maintain long term use. Another characteristic which has proven to be effective in sustainability has been the use of open-source resources instead of proprietary software which can limit creativity in a repository. Objects should be developed with the end user in mind - in many cases a significant number of potential users may have only $56 \mathrm{~K}$ modem access or no reliable internet access at all which is of special concern for global audiences in developing nations. It is important to recognize that not all end-users have access to the latest technologies. However, that does not need to limit a repository's effectiveness if properly designed.

Another information technology factor to consider is that of metadata. Metadata refers to information regarding the data, or learning objects, in this case. It could include things like authorship, media type, copyright, key words, subject matter, attributes of content, etc. All of this is useful for search engines or other repositories to route and utilize the learning objects. The Dublin Core Metadata Initiative (http://dublincore.org/about/) is an organization that is working on the interna- 
tional standardization of defining and characterizing metadata systems, as well as practices, policies and technologies involved. For a specialization in educational learning objects, a metadata system known as Sharable Content Object Reference Model (SCORM) is under development (http://www.adlnet.org/scorm/index.cfm).

\section{Learner Impact}

The next factor in utility consideration is the impact or potential impact a learning object or repository of objects may have on student learning. For greater utility, an object must be able to enhance learning beyond a single audience and/or event. For example, meeting the educational needs of diverse learners in the sciences is one challenge being addressed through electronically delivered learning object repositories. Some learners require basic, introductory materials while others are ready for more advanced instruction. In addition, the educational goals of these learners may vary considerably. Some learners are at the high school level, others seek formal, academic credits to apply towards a graduate degree program or professional certification, still others are simply life-long learners who are curious about a given subject area. Addressing these various levels of education is challenging for any area of study; however, the sciences have the added concern of presenting concepts of an abstract nature as described earlier in this paper. To meet the instructional challenges this characteristic poses, high school science teachers, university instructors, and extension educators need easily accessible, science-based information that helps to illustrate concepts in text, graphic, audio, motion, or multiple modes. Learning objects, and repositories housing collections of learning objects with high utility, provide viable solutions for these overlapping challenges.

Though digital animation learning objects are helpful additions to science instruction, they also have some drawbacks. Specifically, they have been expensive and time consuming to develop because their creation requires several professionals with skills in instructional design, expertise in the content being addressed, and knowledge of the information technology software necessary for designing the learning objects. In spite of these required investments, there are two important strengths of learning objects: their ease of portability and their unparalleled effectiveness in illustrating difficult, scientific concepts to learners. Content experts at the Library of Crop Technology repository (http://croptechnology.unl.edu) determined that computer animated learning objects would be a useful addition to the available plant sciences educational resources for public use (Namuth, Fritz \& King, 2005). Though previous educational research has suggested that animations in and of themselves have limited instructional effectiveness (Park \& Gittelman, 1992), further research indicates that the instructional design principles applied to the animation's design determine the object's impact on learning (Kozma, 1991, 2003; Park \& Gittelman, 1995; Waxman, Lin, \& Michko, 2003). Additional research has shown that animations can enhance student learning. For example, in a comprehensive review of static and animated graphics, Anglin, Hossein, and Cunningham (2004) concluded that students do learn successfully with animated content segments. Other researchers (Dwyer, 1987; Fleming \& Levie, 1993; Mayer \& Moreno, 2002; Moreno \& Mayer, 1999; Rieber 1990a, 1990b) support the finding that animation is a tool which can be designed in ways to stimulate learning. In light of this research, the creation of high-quality, animated objects to elucidate abstract, scientific concepts is shown to be vitally important.

However, what remains uncertain is identifying those specific core instructional characteristics needed for knowledge enhancement when using animation with particular content and specific concepts. Moreno and Mayer (1999) reviewed four studies involving multimedia animations. They determined that more effective student learning resulted when specific cognitive design principles were applied to the animations. These principles are the spatial contiguity principle, that related text and visuals should be grouped closely versus being spaced out on a computer 
screen or page; the temporal contiguity principle which says that the text and visuals are more effective when they are shown or presented at the same time rather than in some other format such as one after the other; the modality principle which says that "students learn better when words in a multimedia message are presented as spoken text rather in printed text" (Mayer, 2001, 134). Similarly, Lih-Juan (2000) explored the specific instructional attributes of animation in presenting concepts in physics. This research found a significant main effect in animation design; in particular, students were able to learn procedural knowledge from the animation designs using visual appeal, pacing, still graphics, and text.

Though each of these studies touts the educational benefits of using animations, there are some limitations that must be noted. The instructional design and course characteristics were varied which limits the generalizability of the results. While the use of animations in these studies was beneficial, in some other cases course content may not lend itself to a graphic display. Additionally, it is important to be realistic concerning resources available for designing effective animations. Without the blend of appropriate content, quality instructional design, and technical skills necessary to develop high-quality learning animations, the effectiveness of the animations may be compromised.

\section{Educator Perception}

The preceding section provided a general overview of student perceptions concerning their exposure to animated learning objects. While students' views about learning objects are important, it is equally important to explore teachers' perceptions of animation utility. Unfortunately, there is a dearth of research examining the instructors' views on the value of animated learning objects. This missing link in research may have hindered the complete incorporation of learning objects into diverse educational environments. It would appear that the educator side of education has been overlooked in the learner-centered educational paradigm. Perhaps a fresh look at the entire "learning system" and all key components to the educational process would launch a fresh wave of creativity and learning enhancement. In light of this, the study of instructors' perceptions concerning the utility and accessibility of computer animation materials embedded in a repository library of learning objects takes on added importance. In particular, it will be critical to examine instructors' perceptions of animated learning objects in relation to the subject matter they are focusing on in their educational activities, spanning traditional classrooms, laboratory sections, distance courses, and even non-credit workshops for adult professional learners as often is the case for extension and other non-formal education instructors. This next section describes a model whereby an animated learning object's utility can be measured or even predicted by focusing on the instructor piece of the holistic learning system.

\section{Educator Roles in Learning Object Adoption}

\section{A Matrix for the Plant Sciences}

Understanding that creating science learning objects requires significant investments of time and money is critical, especially in an era in which those resources in academics are not always readily available. This results in an incredible challenge for those educators wishing to launch out into this arena. Therefore, facilitating opportunities to pool resources across institutions in creating learning objects with a broad utility is required. As summarized earlier in this paper, the specific characteristics of an effective learning object with high utility had not been previously researched.

In order to fill this gap, a study was conducted on educator perceptions of downloadable plant science animated learning objects from a repository. This study also proposed a matrix for measuring an animation's potential adoption and use in long term educational venues (Namuth et al., 2005). This matrix provides a list of qualities which should facilitate and improve the develop- 
ment of animated learning objects in the plant sciences. The matrix was created by members of the Library of Crop Technology team, representing expertise in the science content of the animations, instructional design methods, information technology and educational research. The seven areas addressed were identified based on discussions among this core group. In this study, users of the Library of Crop Technology rated the animations they had downloaded and used in educational settings. The library's initial target audience was comprised of instructors of students 19 years and older. The largest sample of users to the site was this same target group. The remaining respondents to the survey were those involved in both formal and non-formal education. Importantly, the use of the learning objects spanned several different learning contexts and learner age levels, illustrating the many diverse outlets for using science learning objects. In spite of the numerous differences among the respondents in the sample, the animated learning objects received high marks across the board. In addition, survey responses indicate a growing trend of incorporating multi-media into both formal and non-formal educational outlets.

On a Likert scale where $1=$ low quality/low utility and $5=$ high quality/high utility, each user rated the animation repository on six factors: scientific content, organization, created interest in topic, visual appeal, teaching topic, ease of use, as well as an overall rating (see Table 2 for individual item scale descriptions). The speed, or pace, of the science animation was measured using a scale of $1=$ too slow to $5=$ too fast, with $3=$ appropriate pace. Obviously, on this item a value near " 3 " is the goal. For the Library of Crop Technology all of the seven factors were above the mid-point of the scale (3.0), five of the factors were 4.24 or higher, with easy to use falling in the high quality/high effectiveness $(4.56 \mathrm{MN})$ category. Pace of topic $(3.14 \mathrm{MN})$ fell in the mid-point of the scale (2.50-3.49), indicating that respondents found the speed at which animations covered topics to be neither too slow nor too fast. Researchers also asked users to give the animations an overall rating $(1=$ poor, $5=$ excellent $)$; respondents rated animations close to excellent $(4.45 \mathrm{MN})$. Interestingly, the data indicated correlations among each of the items with most factors significantly $(0.05)$ or highly significantly $(0.01)$ related. This indicates that science content, organization, creation of interest in the topic, visual appeal, effectiveness for teaching a topic, and ease of use are all related to the overall perception of the animation's quality. High numbers of referrals of the site to others and repeated visits to the site serve to validate the respondents' high evaluation of the utility and quality of the animations.

The results of this study suggest several areas of focus for the creation and use of animated learning objects in the sciences: organization, creation of interest in the topic, visual appeal, as well as the effectiveness for teaching a topic, and ease of use. Incorporating these characteristics into the design of an animated learning object should increase the likelihood that it will be positively viewed by the end user, both educator and learner.

\section{Scholarship of Learning Objects}

By this point it has probably become clear that of the incorporation of high quality, pedagogically sound learning objects into a repository for widespread usage is not an easy task to undertake. Further complicating matters is the current lack of professional recognition for the faculty involved in these undertakings. A method for providing recognition for the scholarly contributions of faculty has turned into a pressing need. At the same time, with the increasing global use of the Internet and the explosion of both reliable and unreliable information available worldwide, a mechanism for alerting users to the validity of information has become increasingly important. In response to these pressing issues of scholarly recognition and content validity, some peer review options have been introduced.

Merlot (http://www.merlot.org/Home.po) is a clearinghouse type of repository, which also provides a peer review of learning objects. The main purpose for its reviews is to enable other educators to determine which objects best meet their needs. It operates such that an object is submitted 
to an editorial board to determine its priority. From there an object is submitted to reviewers to determine its "Quality of Content, Potential Effectiveness as a Teaching Tool and Ease of Use." This complete process is designed to be much like that of peer review of scholarship, with an emphasis on the end user.

Another model for peer review of learning objects being used is at the Journal of Natural Resources and Life Sciences Education (http://jnrlse.org). This is a journal published through the American Society of Agronomy, an international professional organization for those with careers in the crop and soil science areas. The Journal of Natural Resources and Life Sciences Education has created a model whereby an innovative public learning object can be peer-reviewed. The review is more intensive, much like that of a conventional research article. Three different experts provide the reviews in this model: an expert on the object's content being addressed; an expert who teaches the content to a similar target audience; and an informational technology expert who looks at the technology utilized in the object and to insure it is functioning properly. Once a learning object has successfully gone through this review, it is given a special icon which is added to the object indicating it has been peer-reviewed and in what year. An abstract of the object, describing its goals and target audience is published with the journal, along with a live link back to the actual object itself.

The combination of processes insures science accuracy and pedagogical soundness of the object, also keeping a repository vibrant. This is important for learners seeking accurate information, as well as instructors in search of educationally effective supporting materials. It is analogous to a consumer report or the Good Housekeeping seal of approval. For the content author(s) and supporting team, this peer-review process provides a venue for scholarship recognition and allows them to contribute to the growing public "knowledge base".

\section{Intangible Factors for Sustainability}

The long term sustainability, ultimate effectiveness, and widespread use of learning object repositories depend upon several factors in addition to the quality of the learning objects themselves. These more intangible, but key factors reside at the institutional and at the faculty team levels. Each of these critical pieces in the overall long term commitment to a repository will be discussed next.

\section{Institutional Level Factors}

Markwell and Brooks (2003) looked at stability of biochemistry and molecular biology websites for providing linkable resources in a graduate level course. In a period of 24 months, $20 \%$ of the links had experienced "link rot" and were useless due to significant content change or the pages no longer available. In some cases, a once free public resource now required a fee, figures were not loading, new programming structure was used so old direct links no longer worked and even in two cases the URLs had been converted from sites describing yogurt and amino acids to pornographic sites. In fact, Koehler (2002) reported that the average lifespan of an educational website was merely 4-6 years. Markwell and Brooks (2003) also suggested the adoption of these materials by professional societies to serve as clearinghouses, as well as to give scholarly credibility to the developers. In other words, some larger organization with a vested interest in the creation of sound materials needs to be involved to insure their long term utility.

In addition to providing the long term housing and maintenance aspects for these endeavors, faculty identified other important institutional commitments (Fritz, Boren, \& Egger. in press). They expressed concerns regarding the rewards and annual faculty performance evaluation their own academic institutions rely upon. Faculty perceptions were that at the institutional level there exists a gap for adequately evaluating individual efforts within the context of multi-disciplinary and 
multi-institutional endeavors, such as a learning object repository. Historically, rewards and annual evaluations are based upon faculty activities where individual scholarly contributions are more apparent and measurable. A team oriented project, where the players are geographically and even disciplinarily dispersed is much more complex for measuring an individual's scholarly contributions. However, these intangible institutional factors are vital for continued faculty contributions in learning objects and repositories. In this next section, the intangible factors associated with faculty teams will be discussed.

\section{Team level factors}

Social scientists have studied the ways small groups and teams function for many years (Deutsch, 1949; Katzenbach \& Smith, 1993; Morgan, Salas \& Glickman, 1993; Tuckman, 1965). Researchers have examined cohesion (Gammage, Carron \& Estabrooks, 2001), effectiveness (Janz, Colquitt \& Noe, 1997), team building (Hart \& McLeod, 2003), and various other, similar topics. However, few researchers have explored the development of teams that are comprised of members from distinct organizations and disciplines. In the context of higher education, multidisciplinary teams are becoming more commonplace (Leholm, Hamm, Suvedi, Gray \& Poston, 1999). Some of the motivation for the development of multi-disciplinary teams in higher education is likely related to the emphasis that competitive federal and state grant programs have placed on multi-disciplinary collaboration (Leholm et al., 1999).

A study on team dynamics was conducted with team members involved in the development of learning objects for the Library of Crop Technology (Fritz et al., in press). Participants were from five different universities and had Cooperative Extension appointments in assorted agricultural disciplines. They were brought together initially in response to a call for proposals from a federal agency. While the primary goal of the funded project was to develop a library of learning objects, a secondary purpose was to explore the team-building strategies of the multi-disciplinary, multiinstitutional team that interacted largely via distance. An ethnographic case study was used to capture in-depth descriptions of the culture of the team (Wolcott, 1980). Data collection was both extensive and intensive involving interviews over a two-year period at the beginning, middle and end of the project. Interviews were conducted face-to-face or on the phone, transcribed, verified, and analyzed for themes.

Vital themes that emerged from the study included: motivation for collaboration, timeline, evaluation and rewards, team leader, cohesion, interaction, and trust. These themes will be discussed in-depth in the following section. It is important at this point to note that the key events, outcomes, and reactions of team members in this study were integrated into Tuckman's (1965) small group development model (See Figure 1.) According to Tuckman, small groups tend to follow a particular pattern in forming and performing. This pattern is comprised of four stages: 1) forming - the group comes together for a purpose, 2) storming - the group struggles to establish a productive working relationship, 3) norming - the group establishes standards for accomplishing their goals, 4) performing - the group begins to function well as a whole. The development of this small group, or team, followed Tuckman's (1965) model. The forming stage of this team was characterized by a general aura of excitement about the project. This soon gave way to the storming stage as misgivings and doubt plagued the individual team members while they struggled to work together. This was followed by the norming stage as team members began to trust one another more fully. This allowed the team to move into the performing stage where they were able to perform at their optimal level, resulting in the receipt of a national award. The themes uncovered in each of these stages are discussed in depth in the following section. 
Figure 1: Integration of Tuckman=s (1965) Small Group Development Model into One Team=s Experience

\section{Motivation}

\begin{tabular}{|c|c|c|c|c|}
\hline & Motivation & & & \\
\hline \multirow[t]{3}{*}{ Events } & Proposal Funded & Face to Face & Email Interaction/ & Website Containing \\
\hline & & Meeting & Grant Extended & Lessons Completed \\
\hline & Forming & Storming & Norming & Performing \\
\hline Outcomes & $\begin{array}{l}\text { Minimal } \\
\text { acknowledgment by } \\
\text { own department }\end{array}$ & $\begin{array}{l}\text { Roles \& timelines } \\
\text { clarified, trust built }\end{array}$ & $\begin{array}{l}\text { Recommitment to } \\
\text { project, disclosure of } \\
\text { individual concerns }\end{array}$ & National award \\
\hline Reactions & $\begin{array}{l}\text { Feelings of } \\
\text { excitement over } \\
\text { utility of project for } \\
\text { themselves and for } \\
\text { others }\end{array}$ & $\begin{array}{l}\text { Fear over time } \\
\text { commitment, doubts } \\
\text { about own and others' } \\
\text { abilities to complete } \\
\text { project, concerns over } \\
\text { lack of reward system } \\
\text { and support in home } \\
\text { departments }\end{array}$ & $\begin{array}{l}\text { Renewed } \\
\text { energy dedicated to } \\
\text { project due to persistence } \\
\text { of facilitator, productivity } \\
\text { increases, confusion } \\
\text { related to communication } \\
\text { emerges as a problem, and } \\
\text { concerns over lack of } \\
\text { support in home } \\
\text { departments remain }\end{array}$ & $\begin{array}{l}\text { Satisfaction at a job } \\
\text { well-done, looking for } \\
\text { more opportunities to } \\
\text { work collaboratively, } \\
\text { still concerned over } \\
\text { lack of support from } \\
\text { home departments }\end{array}$ \\
\hline
\end{tabular}


Individual Motivations: Most team members were motivated to participate in the development of learning objects by a desire to further their knowledge of Web-based instruction. Some team members were motivated by their perception of the utility of the learning objects. One said, "This electronic library containing these modules will be valuable to me... a useful, tangible product that I can use in my program." All team members were convinced that creating the learning objects would be necessary as Cooperative Extension deepens its involvement in distance delivery.

Project Timeline: Initially, team members all had intentions of producing a superior set of learning objects that would be housed in a virtual library. As time progressed and good intentions waned, deadlines were frequently missed. All members questioned the team's original timeline, with one member remarking, "Even if we only manage to do a good job completing $80 \%$ of our objectives, I think it will be a successful outcome." The anxiety expressed by team members was consistent with reactions of team members in studies of similar teams (Younglove-Webb, Gray, Abdalla, \& Thurow, 1999).

Team Leader: A key contributing factor to this, and other, team's success in developing the learning objects was the facilitator, or team leader (Burns, 1994; Gersick, 1989; Proehl, 2000; Schrage, 1995; Younglove-Webb et al., 1999). Team members agreed that the consistent coaxing of the team leader was pivotal to the team's success. One team member noted, "I think the person in charge has done an excellent job. She's got the right touch of encouragement and reminding you of the need to deliver." The team leader was steady and consistent in her expectations of members, being careful not to alienate procrastinators by maintaining positive relationships with members who repeatedly missed deadlines. One member reflected, "The leadership was awesome! Unfortunately, we're not all good followers, so I don't think we finished in a timely manner. [The team leader's] patience and the way she encourages was very positive."

By fostering open, trusting relationships with team members, the team leader created a team environment conducive to collaboration (Schrage, 1995). "She's been doing a great job pulling us all together!" said one member. "You have to keep in mind that in order to pull 10 or 15 scientists together, you're going to have to have a lot of nerve and a lot of patience."

Respect for a team leader is not unusual in most functional teams, especially when the leader is viewed as having higher status than the other team members (Meyers, Meyers \& Gelzheiser, 2001; Younglove-Webb et al., 1999). Studies have concluded that team members with the highest status generally dominate communication, are critical, aggressive, and anticipate respect from lower status members (Meyers et al., 2001; Younglove-Webb et al., 1999). Surprisingly, the team leader in this project had the least amount of status among the team members, yet managed to hold their respect and the admiration. This could be due to the team leader's technical expertise and the complex, technical nature of the project.

Team Cohesion: The members started the project by having a face-to-face meeting to get acquainted with one another. At this meeting, they clarified and defined roles, objectives, and timelines, as well as set ground rules for communication - establishing these "ground rules" was critical in achieving team cohesion (Katzenbach \& Smith, 1993; Scholtes, 1991; Younglove-Webb et al., 1999). As one member concluded, "We want to make sure this set of modules [learning objects] doesn't look like a six room house built by six different contractors! We need to have enough interaction so that we have a common view."

Throughout the life of the project, members longed for further face-to-face interactions. Yet, in spite of being located across the country, the team evolved from a mere collection of faculty brought together in response to a call for proposals to a group of scholars committed to developing a sustainable library of learning objects. At the close of the project, one member concluded, "We talk as a group much more often now. Many of the modules [learning objects] reflect the 
thinking of the entire group...the lessons are better than they would have been if they were developed by an individual."

Team Interaction: Communication problems are prevalent in teams that are performing via distance and can negatively impact productivity and cohesion (Armstrong \& Cole, 1995; Kiesler \& Cummings, 2002; Younglove-Webb et al., 1999). One interviewee lamented, "We're all so far away, I think it made it harder for us to put this project on our platter as a real goal."

Feelings of isolation and inconsistent bursts of productivity pervaded every stage of the team's development. Some members attributed these feelings and inconsistent work patterns to not spending more time together in person. Regardless of the cause, the bursts of productivity resulted in an uneven development process across the project due to the integrated nature of the learning objects.

Team Trust: It was evident that the team members felt sufficiently comfortable with one another to disclose their opinions and ideas. This level of trust was important in transcending the distance between members (Tan, Wei, Huang \& $\mathrm{Ng}$, 2000). One member concluded, "If a team doesn't talk very often, they begin to disintegrate as a team, so [the leader] made sure that didn't happen and kept us in a dialogue...that also builds a sense of movement and progress in the group."

The majority of the team members believed that the face-to-face meeting promoted group cohesion. This cohesion became critical later in helping them deal with project challenges and accomplish success (Katzenbach \& Smith, 1993). One member concluded that the use of travel money from the project to bring members together was critical. At those face-to-face meetings, he felt more like a member of a team, and less of a "lone ranger trying to conquer this project."

This team's transformation followed Tuckman's (1965) team development model. The forming and storming stages were fraught with reservations about how the project goals would be achieved; as the team transitioned into the norming and performing stages, trust and camaraderie were widespread.

\section{Evaluation and Rewards}

Working on a specific project as part of a virtual team that is distributed across several institutions often produces an atmosphere of isolation and alienation. This type of 'closed' system offers minimal opportunities for team members to share accomplishments with colleagues and administrators in their home departments who are frequently unaware of the team's existence. This scenario became an overwhelming concern for members in the project. A vital concern was the lack of concrete evaluation methods for colleagues and administrators to use to assess team members' contributions to the project (Frost \& Gillespie, 1998; McKenzie \& Lee, 1998; Wageman, 1995).

The majority of the team members perceived that they were encouraged by their administrators to collaborate; however, their administrators were unprepared to evaluate and reward their efforts to develop the learning objects. One member lamented that the evaluation and reward dilemma may be related to his administrator having difficulty ascertaining whether he was a major player or a just a supporting player, taking credit for the efforts of the other team members. Another member intimated, "We are in a crunch for funding so people get together in order to get certain things done." This member felt that his administrator was supportive of the project because he "likes to see us deliver certain results and if the multi-disciplinary approach is the way to deliver the right results then I'm sure they're going to be favorable to it." With regard to faculty colleagues, no members reported departmental faculty peers as unsupportive, but they characterized them generally unaware of their collaborations. One member summed up his situation by saying, "I'm not sure that they know that I'm involved and I'm not sure that they would care." 
Many of the impediments to this team's success were created by pressures from members' respective institutions. It was clear that members were not motivated to participate in this multidisciplinary project because their participation was valued and rewarded by their administrators or their peers. Rather, the desire to produce learning objects that had utility in their programs drove their commitment. Without a reward structure in place that acknowledges faculty involvement in multi-disciplinary, virtual projects, faculty will continue to be faced with the quandary of participating in collaborative projects that attract external funding, and the need to satisfy department expectations which reward individual efforts (Edwards, 1999; Frost \& Gillespie, 1998; McKenzie \& Lee, 1998).

\section{Conclusions}

In summary, this paper has described different types of learning object repositories and their various missions. It has demonstrated the effectiveness of learning object repositories in enhancing educational experiences for both learners and educators across disciplines. In the plant sciences, animated learning objects can assist learners in grasping complex topics which are better understood through visual demonstration. However, the development of learning objects requires sound pedagogical principles and a large investment of time and money. Therefore, to make the best use of these limited resources, a matrix has been suggested which serves as a guide in the development of a useful and valuable animated object.

One of the greatest challenges facing learning object repositories is their long-term sustainability. With the large investment of both time and finances necessary to create learning objects and their repositories, an extended shelf life is needed to offset these costs. This paper also identified intangible factors at the team and institutional levels which can greatly increase the likelihood of long term success and utility.

Areas for future study into learning object repositories include further testing of the models presented here in both more science contents, as well as in other disciplines. The matrix for plant science learning object utility needs testing in a larger sample, as well as modified for other topic areas. The intangible influences of institutional support and recognition of such faculty endeavors also need to be further characterized and successful models identified.

\section{References}

Anglin, G., Hossein, V., \& Cunningham, K., (2004). Visual representations and learning: The role of static and animated graphics. In D. H. Jonassen (Ed.), Handbook of research on educational communications and technology (pp. 865-912). Mahwah, NJ: Lawrence Erlbaum Associates.

Armstrong, D., \& Cole, P. (1995). Managing distance and differences in geographically distributed work groups. In S. E. Jackson \& M. N. Ruderman (Eds.), Diversity in work teams. Washington, DC: APA.

Burns, C. (1994). Innovative team building: Synergistic human resource development. Administration and Policy in Mental Health, 22(1), 39-48.

Deutsch, M. (1949). An experimental study of the effects of cooperation and competition upon group process. Human Relations, 11, 199-231.

Dwyer, F. M. (1987). Enhancing visualized instruction - Recommendations for practitioners. State College, PA: Learning Services.

Edwards, R. (1999). The academic department: How does it fit into the university reform agenda? Change, $31(5), 17-27$.

Feenstra, G., Ingels, C., Campbell, D., Chaney, D., George, M., \& Bradford. (1997). What is sustainable agriculture ? Retrieved Sept 13, 2005 from http://www.sarep.ucdavis.edu/concept.htm 
Fleming, M., \& Levie, W. H. (1993). Principles from the behavioral and cognitive sciences. Englewood Cliffs, NJ: Educational Technology Publications.

Fritz, S., Boren, A., \& Egger, V. (in press). Diamonds in the rough : A case study of team development across distances, disciplines and institutions. Journal of Extension.

Frost, S. H., \& Gillespie, T. W. (1998). Organizations, culture and teams: Links toward genuine change. New Directions for Institutional Research, 100, 5-15.

Gammage, K. L., Carron, A. V., \& Estabrooks, P. A. (2001). Team cohesion and individual productivity: The influence of the norm for productivity and the identifiably of individual effort. Small Group Research, 32(1), 3-18.

Gersick, C. J. G. (1989). Marking time: Predictable transitions in task groups. Academy of Management Journal, 32(2), 274-309.

Hart, R. K., \& McLeod, P. L. (2003). Rethinking team building in geographically dispersed teams. Organizational Dynamics, 34(1), 352-361.

Janz, B. D., Colquitt, J. A., \& Noe, R. A. (1997). Knowledge worker team effectiveness: The role of autonomy, interdependence, team development and contextual support variables. Personnel Psychology, 50(4), 877-904.

Katzenbach, J. R., \& Smith, D. K. (1993). The wisdom of teams: Creating the high performance organization. Boston: Harvard Business School Press.

Kiesler, S., \& Cummings, J. N. (2002). What do we know about proximity and distance in work groups? A legacy of research. In P. Hinds \& S. Kiesler (Eds.), Distributed work (pp. 57-80). Cambridge, MA: MIT Press.

Koehler, W. (2002) Web page change and persistence — a four-year longitudinal study. Journal of the American Society of Information Science, 53, 162-171.

Kozma, R. (1991). Learning with media. Review of Educational Research, 61(2), 179-211.

Kozma, R. (2003). Technology and classroom practices: An international study. Journal of Research on Technology in Education, 26(1), 1-14.

Leholm, A., Hamm, L., Suvedi, M., Gray, I., \& Poston, F. (1999). Area of expertise teams: The Michigan approach to applied research and extension. Journal of Extension, 37(3). Retrieved September 29, 2003, from http://www.joe.org/joe/1999june/a3.html

Lih-Juan, C., (2000). Attributes of animation for learning scientific knowledge. Journal of Instructional Psychology, 27(4), 228-238.

Markwell, J., \& Brooks, D. (2003) "Link rot" limits the usefulness of web-based educational materials in biochemistry and molecular biology. Biochemistry and Molecular Biology Education, 31(1), 69-72.

Mayer, R. E. (2001). Multimedia learning. Cambridge, United Kingdom: Cambridge University Press.

Mayer, R., \& Moreno, R. (2002). Animation as an aid to multimedia learning. Educational Psychology Review, 14(1), 87-99.

McKenzie, R. B., \& Lee, D. R. (1998). Managing through incentives: How to develop a more collaborative, productive and profitable organization. New York: Oxford University Press.

Meyers, B., Meyers, J., \& Gelzheiser, L. (2001). Observing leadership roles in shared decision making: A preliminary analysis of three teams. Journal of Educational and Psychological Consultation, 12(4), 277-312.

Moreno, R., \& Mayer, R., (1999). Designing multimedia presentations with animation: What does the research say? Proceedings of IEEE MULTIMEDIA systems. Florence, Italy. IEEE Press. (720-725). Retrieved July 22, 2004, from http://www.unm.edu/ moreno/PDFS/Florence.pdf

Morgan, B., Salas, E., \& Glickman, A. (1993). An analysis of team evolution and maturation. Journal of General Psychology, 120(3), 277-291. 
Namuth, D., Fritz, S., \& King, J. (2005). Downloadable learning objects for plant science education: A case study. Manuscript submitted for publication.

Park, O., \& Gittelman, S. (1992). Selective use of animation and feedback in computer-based instruction. Educational Technology Research and Development, 40(4), 27-38.

Park, O., \& Gittelman, S.S. (1995). Dynamic characteristics of mental models and dynamic visual displays. Instructional Science, 23(5-6), 303-320.

Proehl, R. (2000). Cross-functional teams: An innovation or just another committee? Higher Education Management, 11(3), 55-71.

Rieber, L. P. (1990a). Animation in computer-based instruction. Educational Technology Research and Development, 38(1), 77-86.

Rieber, L. P. (1990b). Using animation in science instruction with young children. Journal of Educational Psychology, 82(1), 135-140.

Schaffer, S. P., \& Douglas, I. (2004). Integrating knowledge, performance, and learning objects. Quarterly Review of Distance Education, 5(1), 11-19.

Spector, M. (2002). Knowledge management tools for instructional design. Educational Technology Research and Development, 50(4), 37-46.

Scholtes, P. R. (1991). The team handbook. Madison, WI: Joiner.

Schrage, M. (1995). No more teams! Mastering the dynamics of creative collaboration. New York: Currency Doubleday.

Sicilia, M. A., \& Garcia, E. (2003). On the concepts of usability and reusability of learning objects. International Review of Research in Open and Distance Learning, 4(2). Retrieved September 13, 2005 from http://www.irrodl.org/content/v4.2/sicilia-garcia.html

Tan, B. C. Y., Wei, K. K., Huang, W. W., \& Ng, G. N. (2000). A dialogue technique to enhance electronic communication in virtual teams. IEEE Transactions of Professional Communication, 43(2), 153-165.

Tuckman, B. W. (1965). Developmental sequence in small groups. Psychological Bulletin, 63(6), 384-399.

Wageman, R. (1995). Interdependence and group effectiveness. Administrative Science Quarterly, 40, 145180.

Waxman, H., Lin, M., \& Michko, G. (2003). A meta-analysis of the effectiveness of teaching and learning with technology on student outcomes. Naperville, IL: Learning Point Associates. Retrieved July 22, 2004, from http://www.ncrel.org/tech/effects2/index.html or http://www.ncrel.org/tech/effects2/waxman.pdf

Wolcott, H. (1980). How to look like an anthropologist without actually being one. Practicing Anthropology. 3(1), 6-7, 56-59.

Younglove-Webb, J., Gray, B., Abdalla, C. W., \& Thurow, A. P. (1999). The dynamics of multidisciplinary research teams in academia. The Review of Higher Education, 22(4), 425- 440.

\section{Biographies}

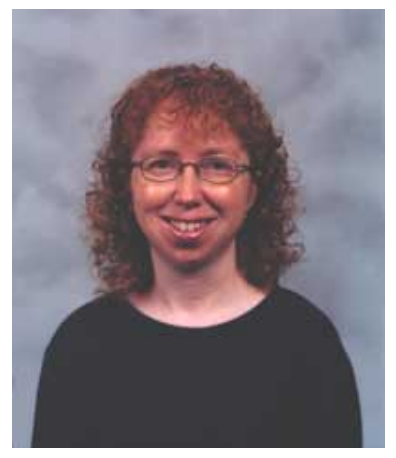

Dr. Deana Namuth is currently the Director of Plant Science Innovative Education in the Department of Agronomy and Horticulture at the University of Nebraska-Lincoln. Her responsibilities include working closely with UNL Agronomy and Horticulture faculty to provide organizational direction in the prioritization, development and maintenance of one-credit distance course modules which serve both academic students and extension clientele. Her graduate background is in plant molecular genetics. She currently co-teaches Crop Genetic Engineering and Crop and Weed Genetics distance modules for non-credit, CEU credit and academic credit learners. Dr. Namuth is involved with 
research on the effectiveness of distance education teaching methods. She has led numerous grant funded projects. She and Dr. Susan Fritz are collaborators on the inter-institutional team which won the 2004 ADEC Excellence in Distance Education Award (http://www.adec.edu ).

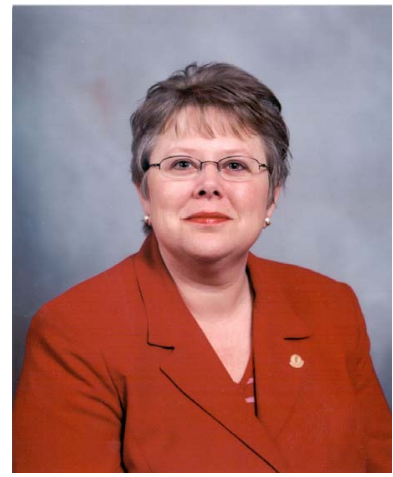

Dr. Susan Fritz serves as the IANR Associate Vice Chancellor and as the Associate Dean for the College of Agricultural Sciences and Natural Resources, University of Nebraska. She also is a tenured professor in the Department of Agricultural Leadership, Education and Communication. She received her B.S. in Business Administration, Masters of Education in Adult Education/Agricultural Education, and Ph.D. in Community and Human Resource Development-Training and Development (1993) from the University of Nebraska. Dr. Fritz is a member of the graduate college and has published and presented in the areas of agricultural education and leadership. Among her most recent scholarly efforts, she, with several colleagues in the Department, edited and published a textbook entitled, Interpersonal Skills for Leadership.

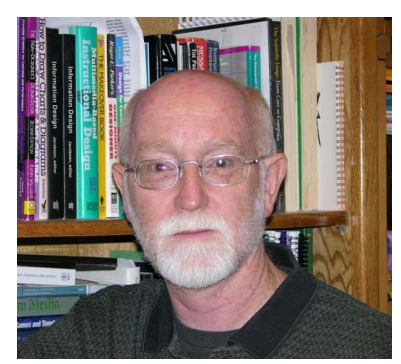

Dr. Jim King is an Associate Professor in the UNL's Department of Agricultural Leadership, Education and Communication. He is working on distance education and new technologies courses. Dr. King graduated from Indiana University in 1981 with an Ed.D. in Instructional Systems Technology. He has been at the University of Hawaii, Indiana University, University of Southern California, and Mashed University in Iran. Dr. King was born in Coral Gables, Florida, married Mary Bruce (they served in the Peace Corps in Iran) and has two children. He has consulted with Arthur D. Little, United Nations Food and Agricultural Organization, W. K. Kellogg Foundation, Ohio Developmental Disabilities Council, Iowa Extension Service, Colorado State University, Rodale Institute, The Pennsylvania State University, Weed Science Society of America, American Society of Agronomy and others. His research interests lie in distance education, multi-media and instructional systems, international agriculture and diffusion and adoption of innovation.

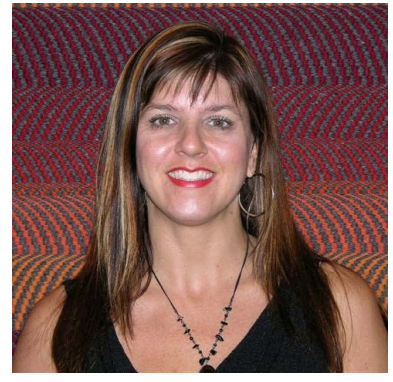

Amy Boren is currently a doctoral candidate in Leadership Studies in the Department of Agricultural Leadership, Education, and Communication at the University of Nebraska-Lincoln. She received her B.A. in French and Spanish at and her M.S. in Leadership Education. Amy has published papers in Psychological Reports, and the Journal of Extension. Her research interests include international migration, community and leadership development in the rural U.S. and Latin America, and leadership theory. 